\title{
Formulation and characterization of proniosomal gels loaded with levofloxacin for dermal drug delivery
}

\author{
Lina k. Mohamed", Mona M. A. Abdel-Mottaleb, Ahmed S. Geneidi \\ Department of Pharmaceutics and Industrial Pharmacy, Faculty of Pharmacy, Ain Shams University, Cairo 11566, \\ Egypt
}

\begin{abstract}
Formulation of proniosomal gels and evaluation of their potential in dermal drug delivery of levofloxacin, an antibacterial drug used to treat complicated bacterial infections. Levofloxacin-loaded proniosomal gels were prepared using coacervation phase separation using nonionic surfactants (spans and tweens). Different parameters of the proniosomal gels were evaluated, including particle size (PS), zeta potential (ZP), drug entrapment efficiency percentage (EE\%), in vitro drug release, and ex vivo permeation studies. Based on the experimental results, the EE\% for the prepared formulas ranged from $32.22 \pm 0.86$ to $54.83 \pm 1.17 \%$. Comparatively to others, levofloxacin could be best encapsulated using span 20. The particle size of the proniosomes ranged from $447 \pm 204 \mathrm{~nm}$ to $1089 \pm 17 \mathrm{~nm}$. Proniosomal gel prepared with span 20 had the smallest vesicle size. The zeta potential range of prepared proniosomes was from $20.95 \pm 0 \mathrm{mV}$ to $60.92 \pm 0.09 \mathrm{mV}$. The prepared formulations were found to have a polydispersity index ranging from $0.198 \pm 3.23$ to $0.967 \pm 0.36$. Almost all of the formulas displayed a linear release profile ranging from 33.028 to 97.56 percent over 4 hours. A higher level of drug deposition was observed with span 80 compared to tween 80 after 6 h: $18.296 \%$ versus $9.44 \%$. The stability study showed that there was no significant change in EE\%, PS, or ZP of levofloxacin proniosomal gels after 3 months of storage. In conclusion, the dermal application of the investigated proniosomal gel formulations demonstrated promising results as nanocarriers for levofloxacin.
\end{abstract}

Keywords: Levofloxacin; spans, tweens; proniosomal gels; dermal drug delivery.

*Correspondence | Lina k. Mohamed; Department of Pharmaceutics and Industrial Pharmacy, Faculty of Pharmacy, Ain Shams University, Cairo 11566, Egypt. Email: khaledlina@yahoo.com

Citation | Mohamed Lk, Abdel-Mottaleb MMA, Geneidi AS, 2021. Formulation and characterization of proniosomal gels loaded with levofloxacin for dermal drug delivery. Arch Pharm Sci ASU 5(2): 288-303

DOI: $10.21608 /$ aps. 2021.109363.1077

Print ISSN: 2356-8380. Online ISSN: 2356-8399.

Received 04 December 2021. Accepted 19 December 2021.

Copyright: ${ }^{\circledR} 2021$ Mohamed et al. This is an open-access article licensed under a Creative Commons Attribution 4.0 International License (CC BY 4.0), which permits unrestricted use, distribution, and reproduction in any medium, provided the original author(s) and source are credited. Published by: Ain Shams University, Faculty of Pharmacy

\section{INTRODUCTION}

Levofloxacin is a member of the third generation of fluoroquinolones with a potent antibacterial effect and broad-spectrum activity against a wide range of bacterial strains. Levofloxacin is a chiral fluorinated carboxyquinoline, which is the $\mathrm{L}$ isomer of ofloxacin. It exerts its antibacterial effect by inhibiting DNA GYRASE and DNA IV topoisomerase resulting in a lethal effect for the cells. Levofloxacin is the drug of choice for treating many complicated infectious diseases. It can effectively treat respiratory tract infections, such as acute sinusitis, acute bronchitis, and pneumonia. In addition, it can be used effectively to treat complicated urinary tract infections caused by resistant strains. Thus, it is an interesting candidate for the treatment of human infectious diseases, but it has several adverse 
effects when taken orally. Levofloxacin's most common adverse effects are gastrointestinal (GI) disturbances and stimulation of the central nervous system (CNS). The hydrophobic properties of levofloxacin present another challenge to its clinical use. Through dermal delivery of levofloxacin, both GI and CNS side effects can be eliminated, decreasing the dose required at the same time $[1,2,3]$.

There have been numerous trials in the field of nanotechnology to develop vesicular drug delivery systems. Liposomes and niosomes are the prototypes of the vesicular systems. Despite their multiple advantages as vesicular delivery systems, liposomes still have major drawbacks in terms of chemical stability issues. The associated issues paved the way for the exploration of the non-ionic surfactant vesicles which are known as niosomes. Even after the niosomes overcome the complications associated with the chemical stability of phospholipids, they still have some physical issues such as aggregation, fusion, or leakage of drug molecules from the vesicles during storage. [4].

Proniosomes are a more stable version of niosomes. They are dry powders that form liposomal dispersion on brief agitation in hot aqueous media. This dry, free-flowing output is more suitable for long-term storage and sterilization. Proniosomes are considered to be an alternative to liposomes and other vesicular systems for entrapping hydrophobic and hydrophilic drugs. Comparing them to other vesicular carriers, they show better cost productivity, chemical and physical stability than liposomes, lower toxicity due to their non-ionic nature, and an easy formulation, which made them a promising industrial product [5]. Proniosomal gel preparations are semisolid liquid crystals made from non-ionic surfactants. In addition, they contain cholesterol and lecithin in lower concentrations. On top of that, cholesterol and lecithin are also present in low concentrations. A minimum amount of organic solvent, like ethanol, and aqueous phase, like water, were needed for formulation. These structures are considered to be liquid crystalline compact niosomes hybrids that can be converted into niosomes in situ after hydration [6].

The semisolid consistency of the proniosomal gel made them easy to be applied directly to the skin. In addition to the penetrationenhancing properties of the added surfactants, proniosomal gels could also serve as an effective vehicle for delivering many medications through the dermal route [7].

\section{MATERIALS AND METHODS}

\subsection{Materials}

Levofloxacin powder sample was provided by Amoun pharmaceuticals, [Egypt]. Ethanol, Propylene glycol, Sodium dihydrogen monophosphate, and Disodium hydrogen diphosphate powders were provided from Nasr pharmaceutical company, Egypt. Pigskin was obtained from the local slaughterhouse. Cholesterol was purchased from the Sigma pharmaceutical company, Egypt. Spectra/Por ${ }^{\circledR}$ dialysis membrane, molecular weight cut-off 12,000-14,000 Da was purchased from Spectrum Laboratories Inc., Rancho Dominguez, and Canada. Span 20, Span 40, Span 60, Span 80, tween 20, Tween 40, Tween 60, Tween 80 were purchased from ADWIA, El-Nasr Pharmaceutical Co (Cairo, Egypt). Solutol ${ }^{\circledR}$ HS 15, Soybean Lecithin was provided as a sample from BASF (Ludwigshafen, Germany).

\subsection{Methods}

\subsubsection{The preparation of proniosomal gels using coacervation phase separation method}

Using the coacervation phase separation technique, preliminary experiments were conducted to select the ideal surfactants, their 
concentration, lecithin, and cholesterol concentrations for the preparation of proniosomal gels. Nine diverse surfactants were screened, namely spans ( $\operatorname{span} 20,40,60$, and 80 ), tweens (tween 20, 40, 60, and 80), and solutol. In these formulations, different concentrations of surfactant were blended with levofloxacin, lecithin, and cholesterol.

As a way of examining the effect of cholesterol amount, different aqueous phases, and surfactants, various quantities of span 20 (250, $300,350 \mathrm{mg}$ ) and a variety of phases (distilled water, phosphate buffer, and glycerol) were used.

The coacervation phase separation system was the most prevalent utilized strategy for the preparation of proniosomal gels. In a beaker: lecithin, levofloxacin, cholesterol $(25 \mathrm{mg}$ for each), and the surfactants (250 mg each) were dissolved in $0.5 \mathrm{~mL}$ of absolute isopropanol. The beaker was covered with a lid to avoid evaporation of the solvent and all the ingredients were warmed over a water bath at $60-70{ }^{\circ} \mathrm{C}$ till the surfactant mixture was dissolved completely. At last, the aqueous phase $(0.16 \mathrm{~mL}$ of distilled water) was added to the blend. At that point, the preparation was warmed again over a water bath followed by cooling the solution overnight at room temperature until the dispersion was converted into gel $[\mathbf{7 , 8}]$. The composition of the proniosomal gels integrated with different quantities of the surfactants, lecithin, and cholesterol was enlisted in Table $\mathbf{1}$.

\subsubsection{Characterization of levofloxacin loaded proniosomal gels}

\subsubsection{Characterization of particle size and zeta potential of levofloxacin loaded proniosomal gels}

In a small glass vial, $100 \mathrm{mg}$ from the proniosomal gel were accurately weighed. The proniosomal gels were appropriately diluted with distilled water before the measurements of the particle size. Average zeta potential and charge on the proniosomal preparations were determined after hydration with phosphate buffer $\mathrm{PH}$ (7.4) at $25{ }^{\circ} \mathrm{C}$ and three runs were carried out. The mean particle size and zeta potential for formulations were determined using a zeta sizer instrument (Malvern instruments, Nano ZS) [9, 10].

\subsubsection{Characterization of the drug entrapment efficiency}

The percentage of the entrapment efficiency in hydrated proniosomes was determined by the centrifugation technique. $100 \mathrm{mg}$ of the proniosomal gel was taken in a dry clean glass tube, and $10 \mathrm{~mL}$ of phosphate buffer (PH 7.4) was added. The fluid suspension was then sonicated in a sonicator bath (Copiague, N, Y, model number SC,52) for almost $30 \mathrm{~min}$. At that point, the hydrated proniosomes were centrifuged at $15,000 \mathrm{rpm}$ at $25{ }^{\circ} \mathrm{C}$ for $30 \mathrm{~min}$. Where levofloxacin-containing niosomes were separated from the unentrapped drug by centrifugation technique. The supernatant containing unentrapped drug was withdrawn and investigated utilizing Shimadzu UV-visible spectrophotometer at $293 \mathrm{~nm}$ with the aid of utilizing phosphate buffer at PH (7.4) as a blank. The percentage of the entrapment efficiency can be calculated as follows by using this equation: $\mathrm{EE}=[(\mathrm{Ct}-\mathrm{Cr}) / \mathrm{Ct}] * 100$ Where, $\mathrm{Ct}$ : the concentration of total levofloxacin, Cf: the concentration of free levofloxacin [11].

\subsubsection{In vitro release of levofloxacin-loaded proniosomal gels.}

By utilizing the dialysis method, the in vitro release profile of levofloxacin-loaded proniosomal gel was determined. The two ends of the dialysis bag were tightly closed with clips. Then, the dialysis bag was soaked in warm water for $10 \mathrm{~min}$ [9].

$100 \mathrm{mg}$ of the proniosomal gel was placed in a previously-swelled dialysis sheet and immersed 
in $100 \mathrm{~mL}$ phosphate buffer which acts as a receptor compartment. Over a magnetic stirrer (Falc), the outer phase was stirred continuously. The heat was provided using a thermostatic hot plate with a magnetic stirrer to maintain the temperature at $37{ }^{\circ} \mathrm{C}$. The samples were withdrawn at previously set time intervals of $0.25,0.5,1,1.5,2,3$, and $4 \mathrm{~h}$ followed by replacement with $2 \mathrm{~mL}$ fresh phosphate buffer to preserve the same total volume. The supernatant was then analyzed spectrophotometrically at 293 $\mathrm{nm}[\mathbf{1 2}]$.

Table 1. The composition of the proniosomal gels integrated with different quantities of the surfactants, lecithin, and cholesterol

\begin{tabular}{|c|c|c|c|c|c|c|}
\hline $\begin{array}{l}\text { Formulation } \\
\text { code }\end{array}$ & $\begin{array}{l}\text { Surfactant } \\
\text { quantity } \\
\text { (mg) }\end{array}$ & $\begin{array}{l}\text { Lecithin } \\
\text { quantity } \\
\text { (mg) }\end{array}$ & $\begin{array}{l}\text { Cholesterol } \\
\text { quantity } \\
\text { (mg) }\end{array}$ & $\begin{array}{l}\text { Drug } \\
\text { quantity } \\
\text { (mg) }\end{array}$ & $\begin{array}{l}\text { Isopropanol } \\
(\mathrm{mL})\end{array}$ & $\begin{array}{l}\text { Distilled } \\
\text { water } \\
(\mathbf{m L})\end{array}$ \\
\hline PN1-S20 & 250 & 25 & 25 & 25 & 0.5 & 0.16 \\
\hline PN2-S80 & 250 & 25 & 25 & 25 & 0.5 & 0.16 \\
\hline PN3-T60 & 250 & 25 & 25 & 25 & 0.5 & 0.16 \\
\hline PN4-T80 & 250 & 25 & 25 & 25 & 0.5 & 0.16 \\
\hline PN5-sol & 250 & 25 & 25 & 25 & 0.5 & 0.16 \\
\hline S20 High & 500 & 25 & 25 & 25 & 0.5 & 0.16 \\
\hline S80 High & 500 & 25 & 25 & 25 & 0.5 & 0.16 \\
\hline T60 High & 500 & 25 & 25 & 25 & 0.5 & 0.16 \\
\hline T80 High & 500 & 25 & 25 & 25 & 0.5 & 0.16 \\
\hline Solutol High & 500 & 25 & 25 & 25 & 0.5 & 0.16 \\
\hline Lecithin High & 250 & 50 & 25 & 25 & 0.5 & 0.16 \\
\hline $\begin{array}{l}\text { Lecithin V. } \\
\text { High }\end{array}$ & 250 & 75 & 25 & 25 & 0.5 & 0.16 \\
\hline $\begin{array}{l}\text { Cholesterol } \\
\text { high }\end{array}$ & 250 & 25 & 50 & 25 & 0.5 & 0.16 \\
\hline $\begin{array}{l}\text { Cholesterol V. } \\
\text { High }\end{array}$ & 250 & 25 & 75 & 25 & 0.5 & 0.16 \\
\hline
\end{tabular}

The PN1-S20:proniosomal gel containing span 20, PN2-S80: proniosomal gel containing span 80, PN3-T60: proniosomal gel containing tween 60, PN4-T80: proniosomal gel containing tween 80, PN5-sol: proniosomal gel containing solutol, S20 High. 


\subsubsection{Ex vivo permeation of proniosomal gels loaded with levofloxacin}

Fresh pig ears were provided from a nearby butcher house directly after the animal sacrifice. Full-thickness skin of the back of pig ears was carefully removed from the underlying subcutaneous lipids and cartilages using a scalpel. The extracted skin was cut into suitable pieces and soaked in phosphate buffer (PH 7.4) for one hour before utilization. Skin permeation tests were done utilizing Franz diffusion cells (diffusion area $=2.7 \mathrm{~cm}^{2}$ and total receptor volume $=25 \mathrm{~mL}$ ). The skin was then mounted in open two-chamber Franz-type diffusion cells loaded with phosphate buffer ( $\mathrm{PH}$ 7.4). The total receptor volume which is equal to $25 \mathrm{~mL}$ of phosphate buffer was taken in the receptor compartment [13].

By utilizing clips, the receptor and the donor compartments were held and kept up at a temperature of $37 \pm 0.5^{\circ} \mathrm{C}$ with the utilization of a water bath. The samples were withdrawn at predetermined time intervals of $0.25,0.5,1,1.5$, $2,3,5$, and $6 \mathrm{~h}$ from the receptor compartment and immediately substituted with an equivalent volume of new receptor solution [11].

The extent of the drug deposited in the epidermal layers was determined. After the completion of the ex-vivo diffusion study, the skin was isolated from the Franz-diffusion cell. The skin was finely partitioned into three definite layers (stratum corneum, epidermis, and dermis). Using adhesive tape, stripping of the skin was performed firmly for successive 15 times in which firm squeezing was finished. By the utilization of surgical blades and forceps, the epidermis was separated from the dermis layer into two separate layers. Tape strips containing stratum corneum and skin layers of both epidermis and dermis were put separately in methanol. Then, they were left to be soaked overnight followed by sonication to extract the deposited drug molecules. The amount of levofloxacin deposited into the stratum corneum, epidermis, and dermis was expressed as a percentage of the total drug amount and was determined utilizing a UV spectrophotometer and there was no interference between different skin components and the UV measurement of the drug [14].

\subsubsection{Stability studies}

Assessment of the drug encapsulation percentage was done by the storage of the proniosomal gels at refrigeration temperature (4 ${ }^{\circ} \mathrm{C}-8{ }^{\circ} \mathrm{C}$ ). Different samples were taken after a period of 3 months and leakage of drug from the formulations was analyzed for drug content using a UV spectrophotometer at $293 \mathrm{~nm}$ [15].

\subsection{Statistical analysis}

All experiments were performed in triplicates and average values were calculated. ANOVA and paired t-tests were used for statistical analysis using Graphpad ${ }^{\circledR}$ software. Differences were considered significant if the $p$ values were less than 0.05 .

\section{RESULTS AND DISCUSSION}

\subsection{Preparation of levofloxacin loaded proniosomal gels}

Several surfactants such as spans and tweens were screened to choose a convenient surfactant for producing gel formulations. Higher amounts of the selected surfactant, lecithin and cholesterol were examined to verify their effects on gel formulation success. As a result of several series of preliminary investigations with different aqueous and organic phases, isopropanol and distilled water were selected as the most suitable solvents for the subsequent experiments. After then, choosing the appropriate surfactants was easy: either spans (span 20 and span 80) or tweens (tween 60 and tween 80) or solutol [16].

Nonionic surfactants are the most common 
type of surface-active agents used in preparing vesicles due to their superior benefits concerning stability, compatibility, and toxicity. By adding cholesterol, more hydrophobic surfactants can form vesicles, the tendency to an aggregate of the surfactant is suppressed, and the gel liquid transition temperature of the lipid bilayer is promoted providing more stability to the vesicle. Phosphatidylcholine is a major component of lecithin. Lecithin plays several crucial roles within the vesicular system: [A] It enhances permeation; [B] It enhances drug entrapment due to its high phase transition temperature [Tc] [C] The high phase transition temperature enhances the compactness of the bilayers with the minimum leakage of the medication molecules out of the vesicles. [D] It aids in producing smaller vesicles as a result of an increase in hydrophobicity. Lastly, the addition of water leads to swelling of the bilayer as a result of the interaction between the water and the polar groups of the surfactants, providing multivesicular, multilamellar, and sphericalshaped structures [17].

\subsection{Determination of particle size and zeta potential of proniosomal gel loaded with levofloxacin}

For physicochemical characterization of proniosomes, the particle size, polydispersity index, and zeta potential were measured. The particle size ranged from $447 \pm 204 \mathrm{~nm}$ to 1089 $\pm 17 \mathrm{~nm}$. Zeta potential plays an important role in determining the physical stability of colloidal vesicular carriers such as pronisomes. The electrokinetic potential of prepared proniosomes ranged from $-20.95 \pm 0 \mathrm{mV}$ to $-60.92 \pm 0.098 \mathrm{mV}$. High ZP values contribute to the stability of the dispersions, while negative values are due to the ionization of the free hydroxyl groups within surfactants and cholesterol. Additionally, lecithin is composed of phospholipids that, when ionized at neutral $\mathrm{PH}$, contribute to its negative charge.
The prepared formulations have a polydispersity index ranging from $0.198 \pm 3.23$ to $0.967 \pm 0.366$. The polydispersity index was not influenced by the formulation composition studied [18]. The results of the particle size, zeta potential, and polydispersity index of the proniosomal gels loaded with levofloxacin were shown in Table 2.

\subsubsection{Effect of surfactant type}

The largest vesicle size was found in tween 80 , while the smallest was found in the span 20 proniosomal gel formulation. This could be explained by the difference in entrapment efficiencies. Where entrapment efficiency of T80 was lower than that of S20. As a result of increasing hydrophobicity of the proniosomal bilayers in span-containing formulations, water intake by niosomes and surface free energy was reduced, resulting in smaller vesicles. Study results suggested that the use of different lipids did not increase the hydrophobicity of tweencontaining formulations, as well as the particle size, remained large. There has been a suggestion that the size of a vesicle is associated with an alkyl chain length of the surfactant, whereby a longer alkyl chain produces larger vesicles seen in tween-containing formulations [19]. Solutol HS 15 is a recently developed non-ionic surfactant. Solutol proniosomal formulations exhibited relatively large particles as tweens. As it has hydrophilic-lipophilic balance (HLB) value nearly to tweens equal to 15 [20].

\subsubsection{Effect of lecithin amount}

The results suggested that the addition of lecithin led to an increase in particle size. A higher surfactant/lipid ratio increased in vesicle size and was related to an overall increase in hydrophilicity [17].

\subsubsection{Effect of surfactant amount}

By adding surfactants to lipid-based vesicles, the size of the vesicles was affected. 
Several factors influence vesicle size, including the concentration of surfactant, the number of carbon chains, and the length of the carbon chains. Due to competition occurring between surfactant molecules and other molecules in the lipid bilayer, the lipid vesicle size increases. Particle size was positively influenced by the amount of surfactant. A possible explanation for this might be the increment in entrapment of the drug resulting in larger vesicles [18].

Table 2. The particle size polydispersity index and zeta potential of the proniosomal gels loaded with levofloxacin

\begin{tabular}{|c|c|c|c|}
\hline Formulation code & $\begin{array}{c}\text { Particle size (nm) } \\
\text { mean } \pm \text { S.D }\end{array}$ & $\begin{array}{c}\text { Polydispersity index } \\
\text { mean } \pm \text { S.D }\end{array}$ & $\begin{array}{c}\text { Zeta potential } \\
\text { mean } \pm \text { S.D }\end{array}$ \\
\hline PN1-S20 & $595 \pm 13$ & $0.226 \pm 0.78$ & $-29.86 \pm 1.56$ \\
\hline PN2-S80 & $766 \pm 66$ & $0.413 \pm 0.23$ & $-25.66 \pm 0.73$ \\
\hline PN5-T60 & $934 \pm 27$ & $0.677 \pm 2.5$ & $-36.23 \pm 0.12$ \\
\hline PN5-T80 & $988 \pm 20$ & $0.555 \pm 1.1$ & $-42.33 \pm 3.56$ \\
\hline PN5-Sol & $807 \pm 9$ & $0.894 \pm 0.66$ & $-34.67 \pm 0.32$ \\
\hline S20 High & $665 \pm 48$ & $0.444 \pm 0.14$ & $-37.23 \pm 5.56$ \\
\hline S80 High & $911 \pm 32$ & $0.676 \pm 0.87$ & $-32.19 \pm 0.45$ \\
\hline T60 High & $1249 \pm 5$ & $0.822 \pm 0.45$ & $-40.14 \pm 8.35$ \\
\hline T80 HIGH & $1089 \pm 17$ & $0.923 \pm 1.56$ & $-60.92 \pm 0.09$ \\
\hline Solutol High & $988 \pm 46$ & $0.967 \pm 0.36$ & $-40.14 \pm 0.13$ \\
\hline Lecithin High & $674 \pm 65$ & $0.334 \pm 0.777$ & $-49.45 \pm 1.56$ \\
\hline Lecithin V. High & $835 \pm 11$ & $0.198 \pm 3.23$ & $-52.19 \pm 3.78$ \\
\hline Cholesterol High & $882 \pm 76$ & $0.888 \pm 0.99$ & $-56.34 \pm 0.84$ \\
\hline Cholesterol very high & $447 \pm 204$ & $0.302 \pm 0.147$ & $-20.95 \pm 0$ \\
\hline
\end{tabular}

\subsubsection{Effect of cholesterol amount}

An increase in the mean vesicle size of the produced proniosomes by increasing cholesterol quantity could be attributed to the increase in the drug load and to the drug being entrapped in the hydrophobic domain of the vesicle, which causes the bilayer molecules in the vesicle to separate, causing the vesicle to become larger in size. In contrast, using a higher concentration of cholesterol resulted in smaller particle sizes and increased hydrophobicity. As the cholesterol levels increased, the hydrophilicity of bilayers 
decreased, limiting the water intake into the core of the vesicles and thereby increasing their size [9].

\subsection{Characterization of the drug entrapment}

\section{efficiency}

The entrapment efficiency values of proniosomal gels ranged from $32.22 \%$ to $54.83 \%$ as shown in Table 3.

Table 3. The drug entrapment efficiency of proniosomal gels

\begin{tabular}{ccc}
\hline Formulation name & Used surfactant & $\begin{array}{c}\text { Percentage of drug entrapment } \\
\text { efficiency }\end{array}$ \\
\hline PN1-S20 & Span 20 & $54.83 \pm 1.17$ \\
PN2-S80 & Span 80 & $51.08 \pm 0.86$ \\
PN5-T60 & Tween 60 & $40.33 \pm 0.77$ \\
PN5-T80 & Tween 80 & $49.44 \pm 1.603$ \\
PN5-Sol & Solutol & $32.22 \pm 0.86$ \\
\hline
\end{tabular}

\subsubsection{Effect of the surfactant type}

The entrapment efficiency of proniosomal gels prepared with spans was observed to be high in comparison to the proniosomes prepared from various types of the tween.

\section{This can be attributed to the following reasons:}

Since the highly lipophilic segment of the drug is entirely encapsulated in the lipid bilayer, this leads to an increase in the drug's entrapment efficiency percent.

The alkyl chain length, phase transition temperatures, and the HLB estimation of the surfactant majorly affect the permeability of proniosomal gels [21].

The EE\% of span 20 was significantly higher than that of span 80. Even though span 80 contains more extended alkyl chains. However, it has unsaturation in its structure, reducing its $\mathrm{EE} \%$. For tween proniosomal gels, tween 80 has a longer saturated alkyl chain than tween 60 .
Also, tween 80 has a lower HLB than tween 60 . This resulted in making the EE\% of tween 80 significantly higher than that of tween 60 . T80 being hydrophilic surfactant with a high HLB value [15] compared to 4.3 in the case of the hydrophobic span 80 , this probably explained the lower entrapment efficiency of T80 compared to span 80 formulations [17]. The results were found to agree with the previous data reported by Shaji J et al. 2016 and Taymouri S et al. 2016 which indicated that the lower the HLB of the surfactant; the higher will be the entrapment efficiency [22]. Span 20 proniosomal formulations exhibited the highest entrapment efficiency. Solutol proniosomal formulations showed relatively low EE\% relatively near to tweens. As it has HLB value nearly to tweens.

It is important to note, that the results relied on present evidence that indicated that the lower the HLB of the surfactant, and the higher the phase transition temperature, the higher will be the entrapment efficiency [20]. Finally, it was concluded that levofloxacin was the best 
encapsulated using span 20 that exhibited the highest entrapment efficiency in comparison to others prepared by tweens [23].

\subsubsection{Effect of surfactant amount}

There was a positive significant effect of the surfactant amount on EE\% for tween 60, tween 80 , and span 20. It could be explained by the increased number of vesicles formed by the increased amount of surfactant. Conversely, EE\% was decreased with the increase in surfactant amount in the case of span 80 and solutol. This could be due to the formation of mixed micelles together with niosomes, which might lead to lower EE\%. Additionally, the permeability of the membrane of vesicles was increased by the surfactant molecules arranged within the lipid bilayer structure. This might introduce pores into the membrane and increase its fluidity, which led to lower $\mathrm{EE} \%$ [18].

\subsubsection{Effect of the amount of cholesterol}

As cholesterol concentration increased in proniosomal gels containing levofloxacin, the entrapment efficiency percent increased significantly. This was a consequence of the simultaneous arrangement of the steroidal skeleton with surfactant molecules that resulted in increased rigidity. As cholesterol concentration increased further, entrapment efficiency also decreased. A potential explanation was that drug molecules and cholesterol compete for space in the limited sites of the bilayer structure of niosomes [24].

\subsubsection{Effect of lecithin amount}

The increase in the concentration of lecithin caused a significant increase in the EE\%. On the other hand, a further increase in the concentration of lecithin caused a decrease in the $\mathrm{EE} \%$. Nevertheless, a detailed examination of the structure of lecithin showed that double bonds in nonhydrogenated phosphatidylcholine allow the chains to bend. The niosomal membrane is formed when they are assembled. Due to that, the membrane permeability increased, resulting in a decrease in gel encapsulation. However, the saturation of the double bond and the presence of hydrogenated lecithin causes bilayer molecules to be assembled resulting in increased rigidity and a reduction in permeability, consequently increasing $\mathrm{EE} \%$. The effect of using different concentrations of surfactants, cholesterol, and lecithin on the entrapment efficiency of the proniosomal gels was shown in Fig. 1.

\subsubsection{In vitro release of levofloxacin loaded proniosomal gels}

A sustainable drug release profile for approximately $4 \mathrm{~h}$ was achieved by incorporating the drug molecules into proniosomal gels. It was evident that levofloxacin was released from the proniosomes with an initial phase release pattern followed by a sustained release pattern. The initial rapid discharge might be due to the desorption of the drug molecules that were present on the niosome surfaces. Additionally, it has been reported that this drug explosion occurred because the highly ordered lipid particles could not accommodate large amounts of drugs. [12].

The release profile of proniosomal gels showed an increase in drug release accompanied by the use of tweens due to their high HLB value. It could be explained by the fact that these hydrophilic surfactants have better solubilizing power towards hydrophobic solutes as compared to hydrophobic surfactants as spans. As such, this idea was a reasonable clarification for the lower drug release rates observed with span formulations in comparison to tween formulations. Solutol proniosomal formulations showed high release values relatively near to tweens. As it has an HLB value nearly to tweens [25]. The release data for the proniosomal gels was illustrated in Fig. 2. 


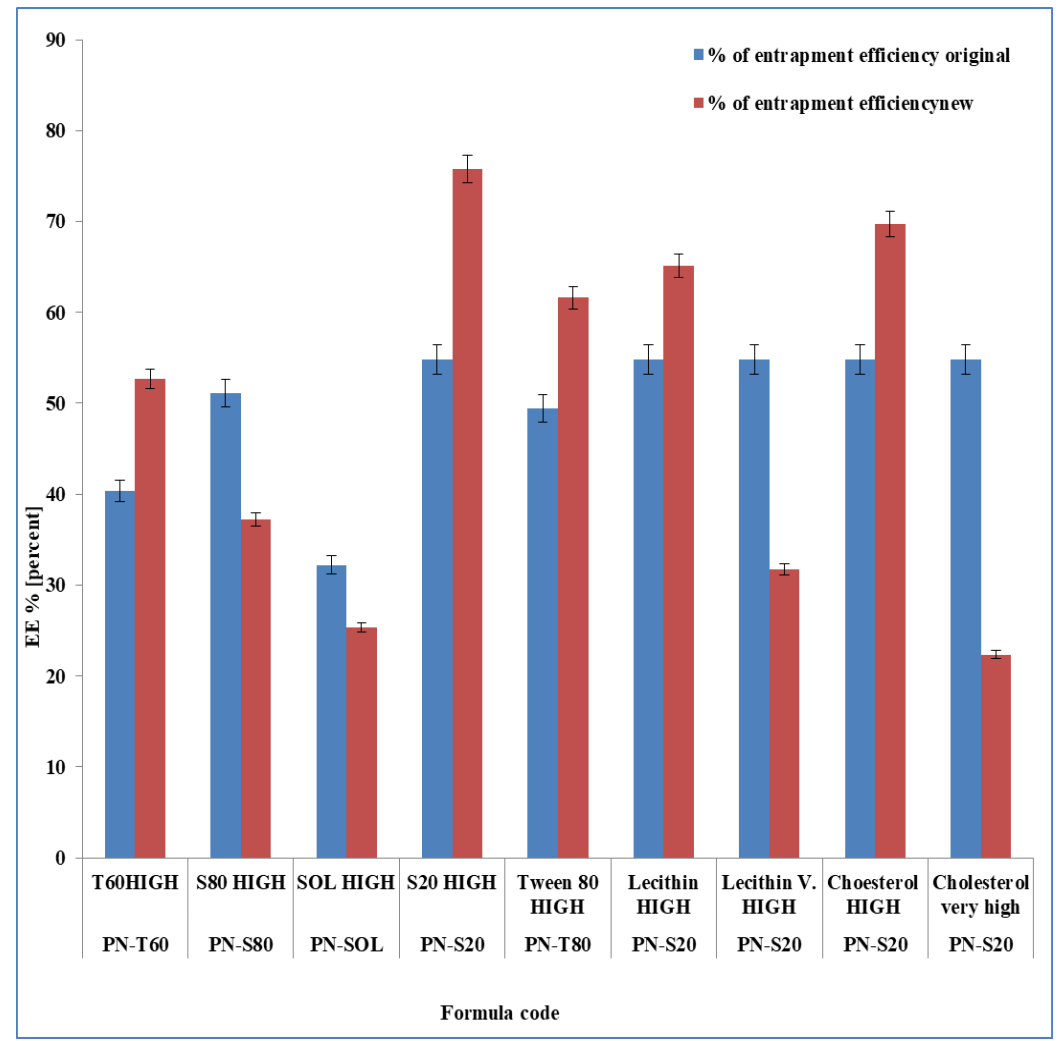

Fig. 1. The effect of using different concentrations of surfactants, cholesterol, and lecithin on the entrapment efficiency of the proniosomal gels

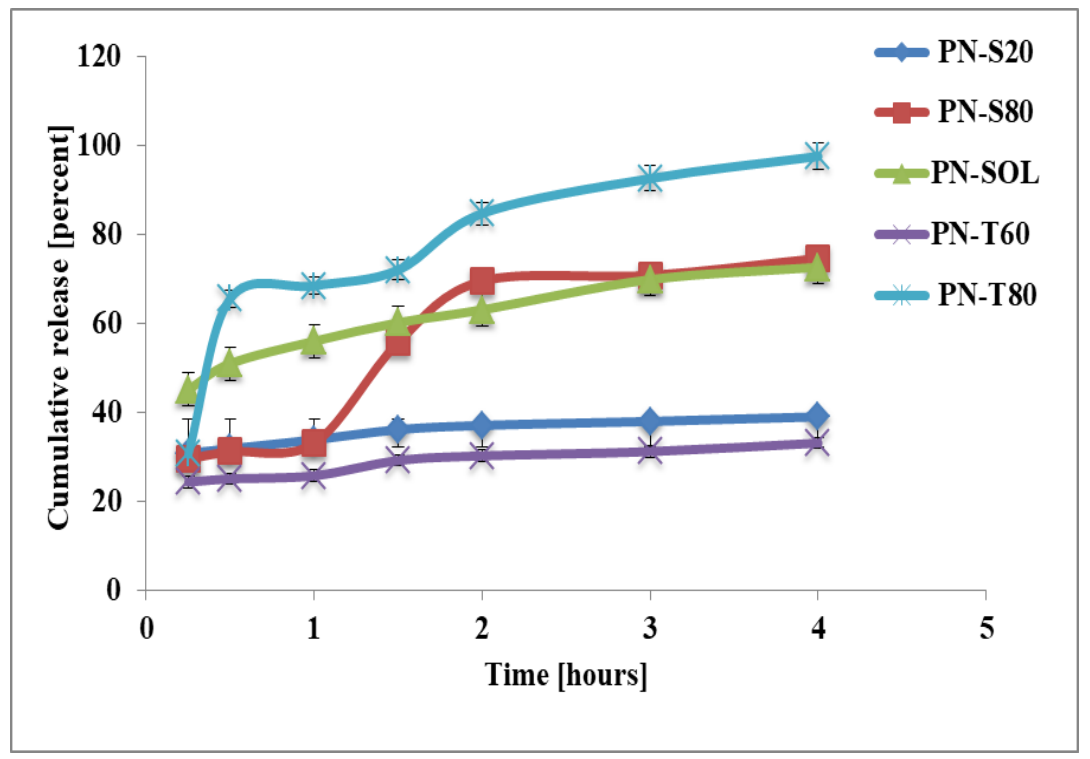

Fig. 2. The in vitro drug release data of the proniosomal gel formulations 


\subsubsection{Type of surfactant}

There was a linear release of drug in the majority of formulas from $33.028 \%$ at the minimum to $97.56 \%$ at the maximum over 4 hours. Proniosomes prepared from tween 60 and 80 exhibited alkyl chain length-dependent release. As a result of the unsaturation in the alkyl chains in span 80 , the release from the proniosomal gel of span 80 was higher than that of span 20 [26].

\subsubsection{The effect of surfactant amount}

The release of the drug from the proniosomal gel was increased by increasing the concentration of span 20 and span 80 . In contrast, the release of medication from the proniosomal gel was significantly diminished by increasing the concentrations of tween 60, tween 80, and solutol.

Surfactants with variable concentrations could greatly affect the release patterns of proniosomal gels. This could be clarified depending on the different properties of the surfactants. In addition to their variable bilayer flexibility, they also exhibit a diverse affinity to drug molecules, which might explain this observed differentiation in the results [26].

The effect of the amount of the surfactant on the in vitro release of the proniosomal gels was shown in Fig. 3.

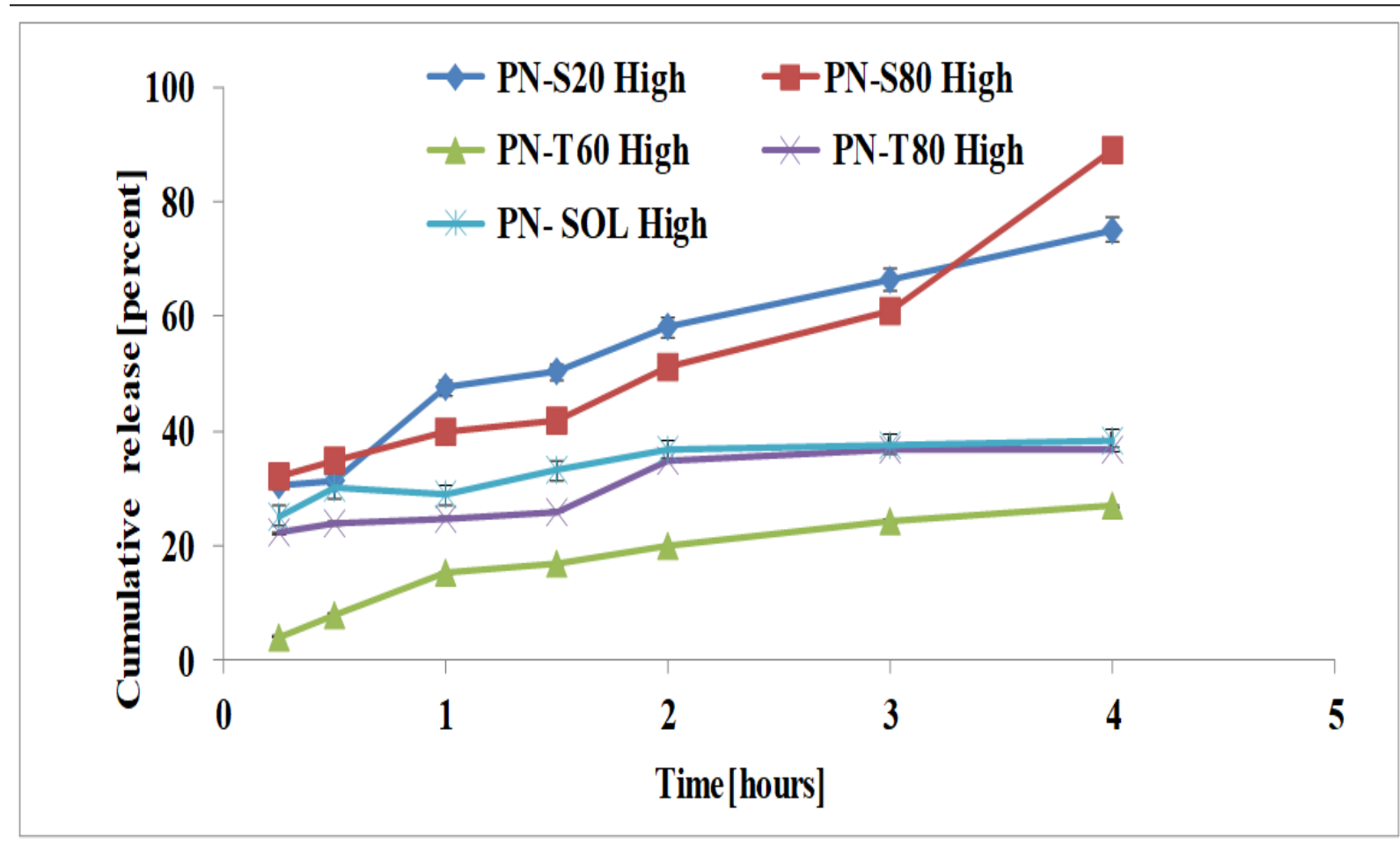

Fig. 3. The drug release data of the proniosomal gel using a higher quantity of surfactants 


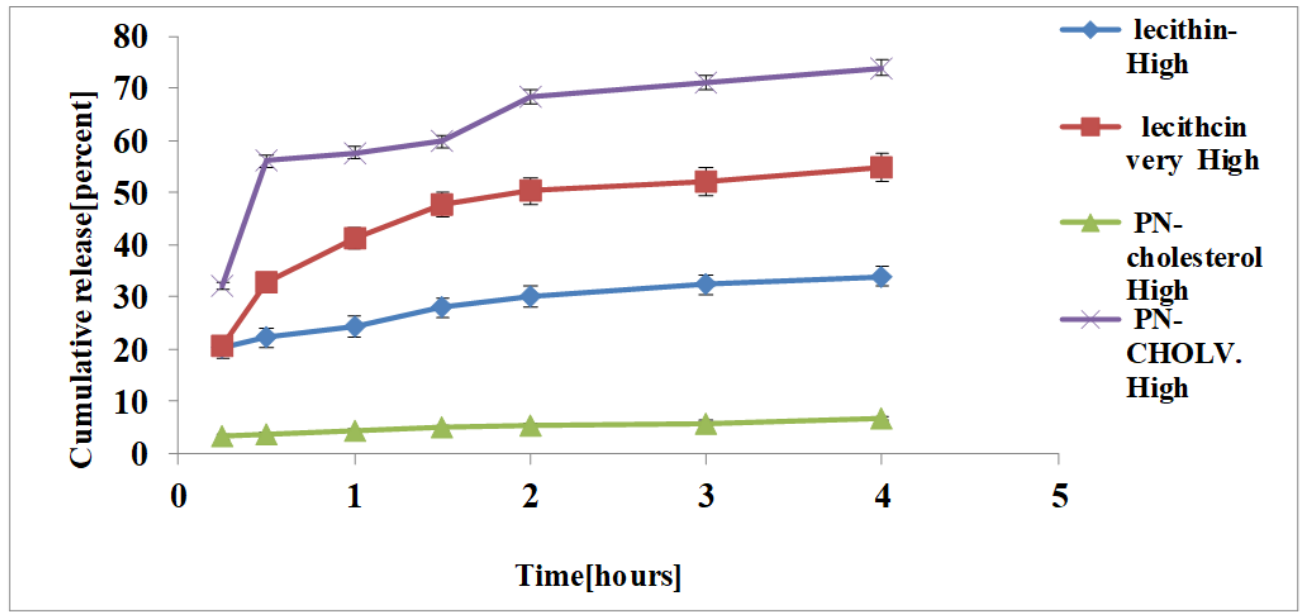

Fig. 4. The drug release data of the proniosomal gel using a higher quantity of lecithin and cholesterol

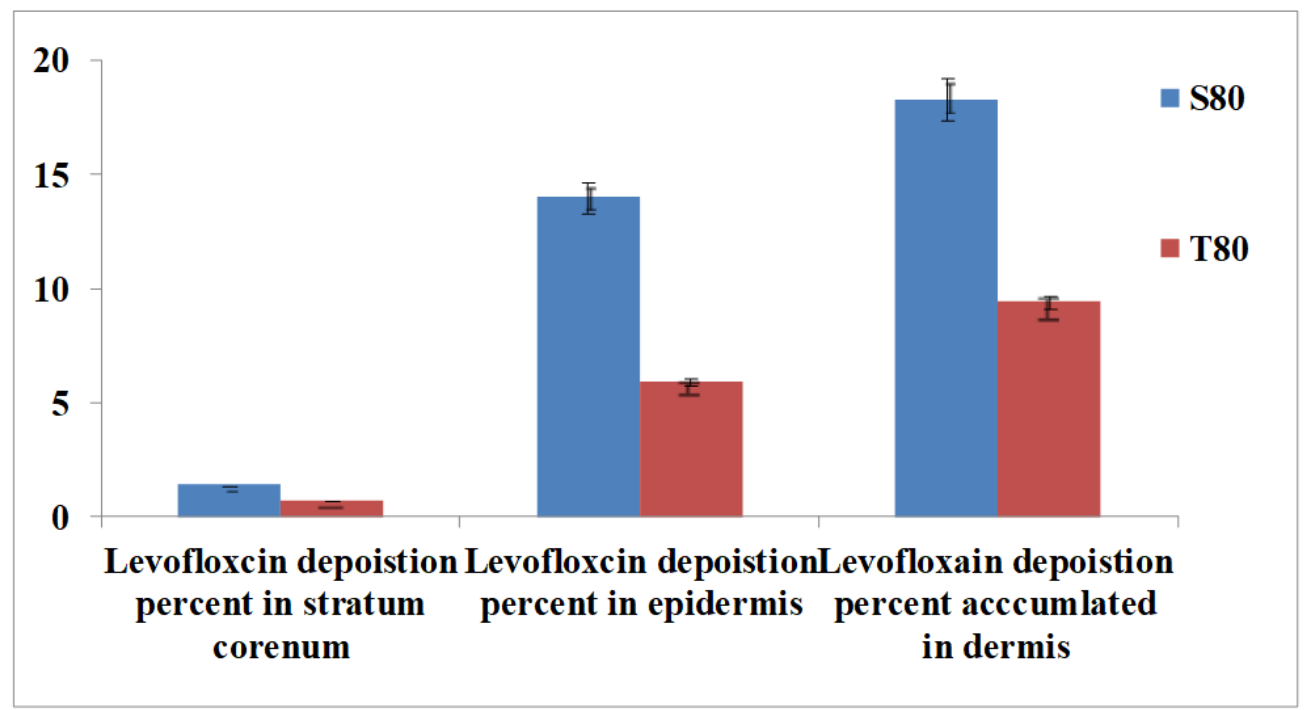

Fig. 5. The percent of the drug deposition in stratum corneum, epidermis, and dermis reflecting the ex vivo deposition for the selected formulae

\subsubsection{Effect of lecithin amount}

Varying the concentration of lecithin had a great effect on the proniosomal gel release rates. This could be further clarified by the fact that lecithin functions as a cosurfactant that aids in the formation of proniosomal vesicles and subsequently enhances the release of drug molecules from vesicles. It increases the hydrophobicity of the vesicles so And increases the permeation of the medications. Lecithin also acts as a penetration enhancer. As a result, increasing its concentration might enhance medication release [27].

\subsubsection{Effect of cholesterol amount}

The elevated cholesterol content resulted in a decreased drug release effect in comparison to the other proniosomal gel containing higher cholesterol amounts. A potential explanation could be that an initial increment in cholesterol amounts resulted in a thicker lipid bilayer that acts as a barrier to drug release In contrast, cholesterol concentrations that exceeded a certain level might disrupt the regular linear structure of 
the vesicular membrane, causing increased drug release [21]. The effect of increasing the amount of cholesterol and lecithin on the in vitro release of proniosomal gels was shown in Fig. 4.

\subsection{Ex vivo/ permeation studies}

In comparison to tween 80 , span 80 showed a higher percentage of drug penetration across various skin layers after six hours. Tween's lower lipophilic nature compared with span might contribute to that. Nonionic surfactants improve penetration by acting as penetration-enhancing agents. Where they interact with the intercellular lipophilic barrier of the stratum corneum, thereby barring its function [11].

The more the drug molecules are deposited in skin layers with proniosomal gels, the greater their potential to bypass the stratum corneum's barrier function and to deliver the drug effectively. This was also because isopropanol act as a penetration enhancer and its branched structure acts as a cosurfactant, allowing the drug to penetrate more deeply into the bilayer [12]. The extent of the drug deposited in the skin layers was shown in Fig. 5.

\subsection{Stability studies}

In the present study, stability studies were conducted on all formulations. The proniosomal gels were stored at $4{ }^{\circ} \mathrm{C}$ for 3 months to observe changes in \%EE, PS, and ZP. After storage, there have been slight changes in entrapment efficiency and physicochemical characteristics [10]. The effect of the storage conditions on the entrapment efficiency and the particle size of proniosomal gels loaded with levofloxacin was shown in Figs. 6\&7.

\section{Conclusion}

Using the coacervation phase separation method, proniosomal gels were prepared with different nonionic surfactants, including spans and tweens, combined with cholesterol and lecithin measured in determining amounts. The experimental results showed that the $\mathrm{EE} \%$ for the prepared formulae ranged from $32.22 \pm 0.86$ to $54.83 \pm 1.17 \%$. The smallest vesicle size was found in proniosomal gels prepared with span 20 . A significant increase in entrapment efficiency percent was observed for proniosomal gels containing levofloxacin after the initial increase of lecithin and cholesterol concentrations. While the further increase in their concentration resulted in a decrease in $\mathrm{EE} \%$. There was a positive significant effect of using high surfactant concentration on the entrapment efficiency percent in tween 60, tween 80, and span 20. Conversely, the EE\% was significantly decreased with an increase in surfactant amount in the case of span 80 and solutol. The particle size of the proniosomes ranged from $447 \pm 204 \mathrm{~nm}$ to 1089 $\pm 17 \mathrm{~nm}$. Proniosomal gels prepared with span 20 had the smallest vesicle size. A positive effect was seen on the particle size of the produced proniosomes when the concentration of surfactant and lecithin was increased. The initial increase in cholesterol quantity led to an increase in the mean size of the proniosomes produced. By contrast, higher concentrations of cholesterol resulted in an increase in hydrophobicity and smaller vesicles. The zeta potential of prepared proniosomes ranged from $-20.95 \pm 0 \mathrm{mV}$ to $60.92 \pm 0.09 \mathrm{mV}$. The prepared formulations had a polydispersity index ranging from $0.198 \pm 3.23$ to $0.967 \pm 0.36$. A sustained drug release profile was evident after the incorporation of the drug molecules into the proniosomal gels for approximately four hours. According to the results, most formulas had a linear release profile ranging from $33.028 \%$ to $97.56 \%$. The release rate of the drug from the proniosomal gel was increased by increasing span 20 and spans 80 concentrations; however, it was decreased by increasing the concentrations of tween 60 , tween 80 , and solutol. By varying the concentration of lecithin, the release rate of the proniosomal gels 
increased, while the elevated cholesterol content resulted in a reduced release of the drugs in contrast with the other proniosomal gel with a higher concentration of cholesterol. Span 80 showed a higher percentage of drug deposition (18.296\%) across different skin layers compared to tween $80(9.44 \%)$ after six hours. The stability study did not reveal any significant changes in levofloxacin EE\%, PS, or ZP.

Study results reported that proniosomal gels could be potentially promising carriers for dermal delivery of levofloxacin to improve the therapeutic effectiveness and increase patient compliance.

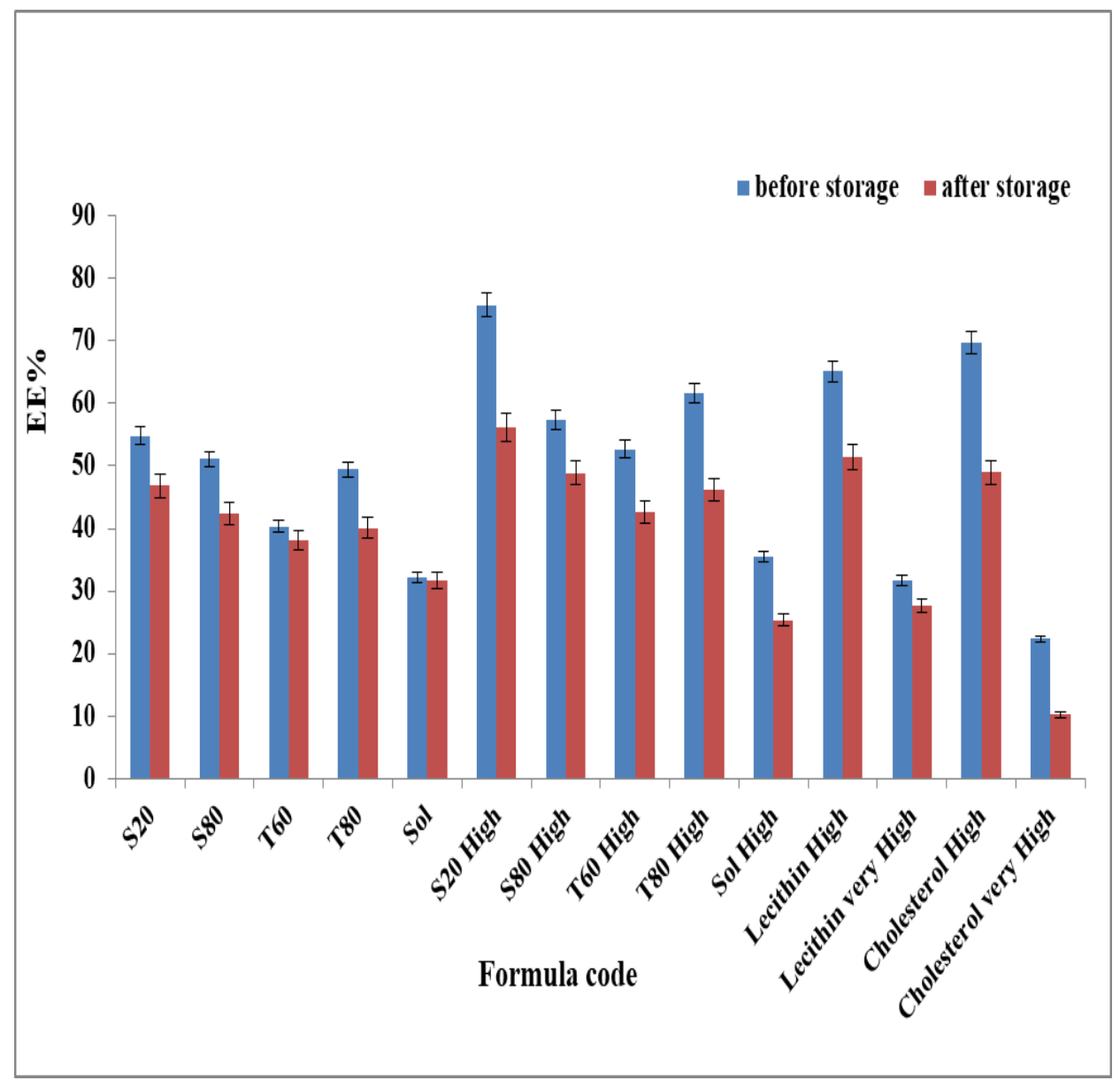

Fig. 6. The effect of the storage conditions on the entrapment efficiency of proniosomal gels loaded with levofloxacin 


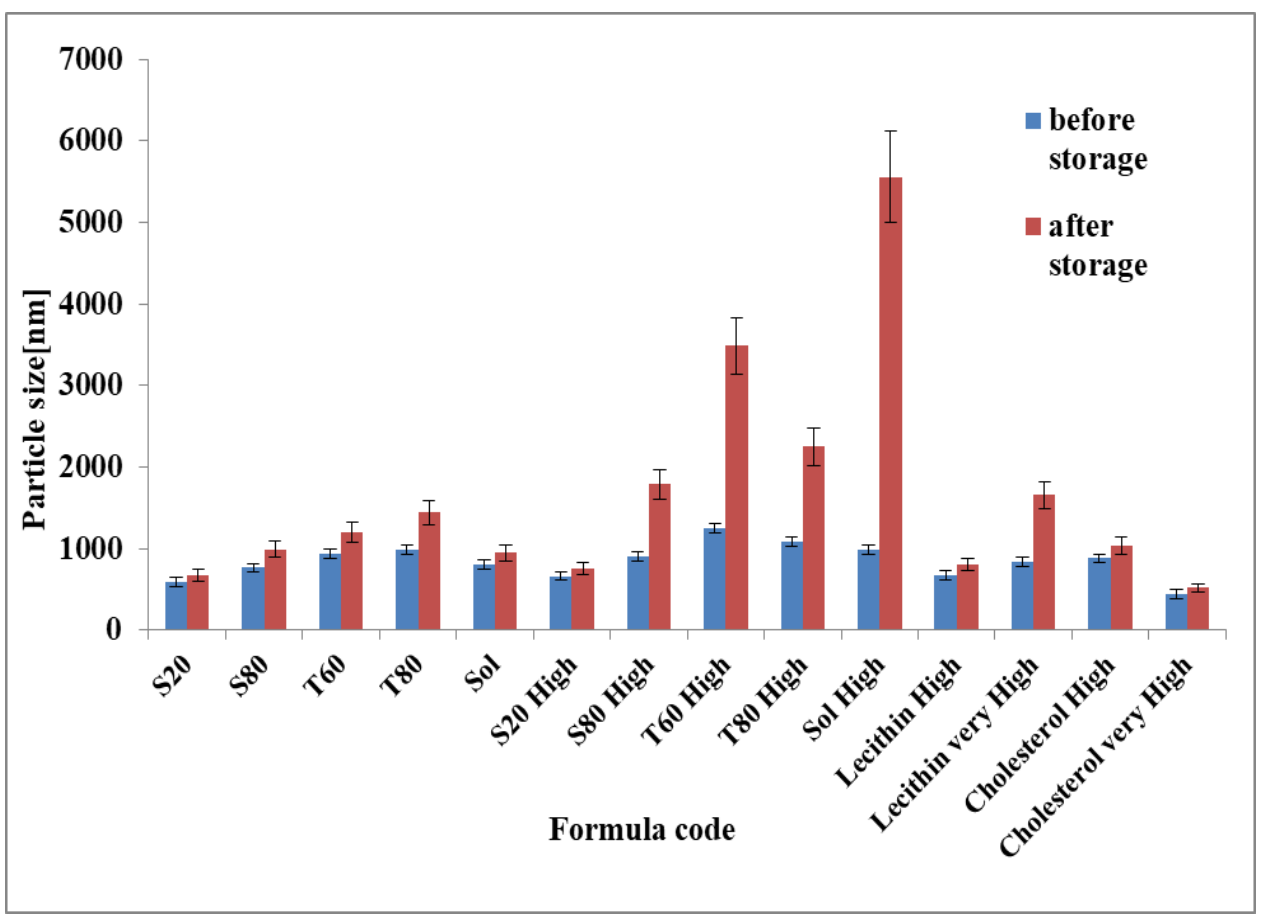

Fig. 7. The effect of storage conditions on the particle size of the proniosomal gels

\section{Declarations}

\section{Ethics approval and consent to participate}

Not applicable

\section{Consent to publish}

All authors have read and agreed to the published version of the manuscript.

\section{Availability of data and materials}

Data analyzed during this study are all included in the main manuscript.

\section{Competing interests}

No competing interests were declared by the authors.

\section{Funding statement}

No funding source was received

\section{REFERENCES}

1. Fayyaz M, Yousuf RI, Shoaib MH, Ali T, Nasiri I, Ashraf N. Quality evaluation and in vitro interaction studies between levofloxacin 250mg and diclofenac sodium $50 \mathrm{mg}$ tablets. Pak J Pharm
Sci. 2015;28(1):119-28.

2. Valizadeh A, Shirzad M, Pourmand MR, Farahmandfar M, Sereshti H, Amani A. Levofloxacin nanoemulsion gel has a powerful healing effect on the infected wound in streptozotocin-induced diabetic rats. Drug Deliv Transl Res. 2020;292-304.

3. Tunitskaya VL, Khomutov AR, Kochetkov SN, Kotovskaya SK, Charushin VN. Inhibition of DNA Gyrase by Levofloxacin and Related FluorineContaining Heterocyclic Compounds. Acta Naturae. 2011;3(4):94-9.

4. Yasam VR, Jakki SL, Natarajan J, Kuppusamy G. A review on novel vesicular drug delivery: Proniosomes. Drug Deliv. 2014;21(4):243-9.

5. Radha G, Rani Ts, Sarvani B. A review on proniosomal drug delivery system for targeted drug action. J Basic Clin Pharm. 2013;4(2):42.

6. Patel NN, Vikram, Roopchandani K, Gupta A, Gupta A. Proniosomes for improved transdermal drug delivery - A review. Pharma Res. 2013;8(2):62-82.

9. Pankaj S, Rini T, Dandagi P. M. Formulation and 
evaluation of proniosome based drug delivery system of the antifungal drug clotrimazole. Int $\mathbf{J}$ Pharm Sci Nanotechnol. 2013;6(1):1945-51.

10. Saber A, Abu M, Khalifa M, Khalifa A, Dawaba HM. Proniosomal gel - mediated topical delivery of fluconazole: Development, in vitro characterization, and microbiological evaluation. 2019.

11. Sambhakar S, Paliwal S, Sharma S, Singh B. Formulation of risperidone loaded proniosomes for effective transdermal delivery: An in-vitro and invivo study. Bull Fac Pharmacy, Cairo Univ. 2017;55(2):239-47.

12. Lather V, Sharma D, Pandita D. Proniosomal gelmediated transdermal delivery of bromocriptine: In vitro and ex vivo evaluation. J Exp Nanosci. 2016;11(13):1044-57.

13. Nanda S, Saroha K, Sharma B. Formulation, evaluation and optimization of transdermal gel of ketorolac tromethamine using face-centered central composite design. Int $\mathbf{J}$ Pharm Pharm Sci. 2014;6(4):133-9.

14. Ashok, Matei, Mohamed, Habiduddin, Rajan, Jukanti.2016 Formulation and of proniosome based transdermal gel of sumatriptan succinate 6,224-235.

15. Ramkanth S, Chetty CM, Sudhakar Y, Thiruvengadarajan VS, Anitha P, Gopinath C. Development, characterization \&amp; in vivo evaluation of proniosomal based transdermal delivery system of Atenolol. Futur J Pharm Sci. 2018;4(1):80-7.

16. Benipal G. Design, development, and evaluation of proniosomal gel of an antifungal drug Ketoconazole. Int J Pharm Sci Rev Res. 2015;31(2):265-77.

17. Abdelbary GA, Amin MM, Zakaria MY, Abdelbary GA, Amin MM, Zakaria MY. Ocular ketoconazole-loaded proniosomal gel : formulation , ex vivo corneal permeation and in vivo studies $2017 ; 7544$.

18. Eldeeb AE, Salah S, Ghorab M. Proniosomal gelderived niosomes: an approach to sustain and improve the ocular delivery of brimonidine tartrate; formulation, in-vitro characterization, and in-vivo pharmacodynamic study. Drug Deliv. 2019;26(1):509-21.

19. Rajabalaya R, David SR, Chellian J, Yun GX, Rajabalaya R, David SR, et al. Transdermal delivery of oxybutynin chloride proniosomal gels for the treatment of overactive bladder .2016;7544.

20. Knudson W, Knudson W, Clodfelter K, Lu B, Weinstein RS. Solutol HS 15, Nontoxic Polyoxyethylene Esters of 12-Hydroxystearic Acid, Reverses Multidrug Resistance. Cancer Res. 1991;51(3):897-902.

21. Abdelbary GA, Amin MM, Zakaria MY. Ocular ketoconazole-loaded proniosomal gel: Formulation, ex vivo corneal permeation and in vivo studies. Drug Deliv. 2017;24(1):309-19.

22. Chauhan SB, Naved T, Parvez N. Formulation development and evaluation of proniosomal gel of ethinylestradiol and levonorgestrel for antifertility treatment. 2019;12(1):0-4.

23. Sandeep G, Vasavi Reddy D, Devireddy SR. Formulation and evaluation of fluconazole proniosomal gel for topical administration. J Appl Pharm Sci. 2014;4(7):98-104.

24. Rajabalaya R, Leen G, Chellian J, Chakravarthi S, David SR. Tolterodine tartrate proniosomal gel transdermal delivery for overactive bladder. Pharmaceutics. 2016;8(3).

25. Ahmad H, Arya A, Agrawal S, Dwivedi AK. Novel lipid nanostructures for delivery of natural agents with antioxidant, anti-inflammatory, and antistroke potential: Perspectives and outcomes. Nanostructures for Oral Medicine. Elsevier Inc.; 2017. 577-605 p.

26. Khalil RM, Abdelbary GA, Basha M, Awad GEA, El-Hashemy HA. Design and evaluation of proniosomes as a carrier for ocular delivery of lomefloxacin $\mathrm{HCl}$. J Liposome Res. 2017;27(2):118-29.

27. Lather V, Sharma D, Pandita D. Proniosomal gelmediated transdermal delivery of bromocriptine: in vitro and ex vivo evaluation. 2016;8080. 